\title{
Adipose Tissue Abnormalities in Cystic Fibrosis: Noninvasive Determination of Mono- and Polyunsaturated Fatty Acids by Carbon-13 Topical Magnetic Resonance Spectroscopy
}

\author{
ROBERT J. DIMAND, CHRIT T. W. MOONEN, SIMON C. CHU, E. MORTON BRADBURY, \\ GEOFFREY KURLAND, AND KENNETH L. COX \\ Departments of Pediatrics [R.J.D., G.K., K.L.C.] and Biological Chemistry [C.T.W.M., S.C.C., E.M.B.], \\ University of California Davis, Davis, California 15213
}

\begin{abstract}
Natural abundance in vivo carbon-13 topical magnetic resonance (TMR) spectroscopy was used to assess human adipose tissue stores of essential (polyunsaturated) fatty acids. TMR spectra were obtained from 17 normal volunteers and nine cystic fibrosis patients using an Oxford TMR-32 with a surface coil that sampled tissue less than $1 \mathrm{~cm}$ below the surface of an extremity. Spectra were taken of lower leg adipose tissue. Polyunsaturated fatty acid content was determined by comparing peak heights of the polyunsaturated peak (internal unsaturated carbons, $128 \mathrm{ppm})$ to $\mathrm{C}-1$ carboxyl groups (173 ppm). Monounsaturated fatty acid content was determined by subtracting the polyunsaturated peak from the peak observed for all unsaturated carbons (external unsaturated carbon, $130 \mathrm{ppm}$ ) and dividing this ratio by the carboxyl peak. In vivo TMR of normal volunteers resulted in observed polyunsaturated fatty acid content of $17.8 \pm 2.1 \%$ and a monounsaturated content of $44.8 \pm 3.8 \%$. The polyunsaturated and monounsaturated fatty acid content of adipose tissue from the cystic fibrosis patients was $15.0 \pm$ $2.0 \%$ ( $p<0.005$ versus normal volunteers) and $47.8 \pm$ $6.5 \%$ (NS), respectively. One cystic fibrosis patient without fat malabsorption had decreased adipose polyunsaturateds, whereas another patient on high calorie gastrostomy feeds had normal levels. Carbon-13 TMR spectroscopy is a sensitive, noninvasive technique for determining essential fatty acid status in subcutaneous adipose tissue of patients with cystic fibrosis. (Pediatr Res 24: 243-246, 1988)
\end{abstract}

Abbreviations

TMR, topical magnetic resonance CF, cystic fibrosis

PUFA, polyunsaturated fatty acids

MUFA, monounsaturated fatty acids

EFA, essential fatty acids

K, kilobytes

The PUFA stored in adipose tissue are composed primarily of EFA, linoleic acid $(18: 2 \mathrm{n} 6)$ and to a much smaller extent, arachidonic acid (20:4n6) (1). EFA have three main uses: as prostaglandin precursors, components of cell membranes, and for

Received August 20, 1987; Accepted April 18, 1988.

Correspondence and requests for reprints Dr. Robert J. Dimand, Children's Hospital of Pittsburgh, 3705 Fifth Avenue, Pittsburgh, PA 15213.

Supported in part by NIH Regional Resource Grant RR02479. cholesterol esterification. Numerous studies have demonstrated abnormalities of EFA in circulating triglycerides and phospholipids in patients with $\mathrm{CF}(2-4)$. Although most investigations have focused on these circulating lipid classes, some studies have demonstrated abnormal levels of EFA stored in adipose tissue of $\mathrm{CF}$ patients with malabsorption $(5,6)$. Because percutaneous adipose tissue biopsies are invasive and not a routine pediatric procedure, the recent studies have been limited to postmortem adipose samples of both CF patients and control children (6). The relationship between abnormal EFA status and fat malabsorption remains unclear. Low levels of EFA have been noted in serum and membrane lipids in CF patients both with and without steatorrhea $(3,4,7,8)$. A recent report demonstrating abnormal in vitro turnover of arachidonic acid in lymphocytes from $\mathrm{CF}$ patients suggests the possibility of a fundamental abnormality of essential fatty acid metabolism (9).

TMR spectroscopy has been used for in vivo studies of human pathophysiology for several years $(10,11)$. The majority of these studies has used the ${ }^{31} \mathrm{P}$ nucleus, providing information on high energy phosphates, inorganic phosphate, and tissue $\mathrm{pH}$ (11). The ${ }^{13} \mathrm{C}$ nucleus also has paramagnetic properties, but has two major disadvantages when compared to ${ }^{31} \mathrm{P}$. First, the low natural abundance (about $1.1 \%$ ) of ${ }^{13} \mathrm{C}$ compromises sensitivity necessitating larger quantities of sample material. Second, ${ }^{13} \mathrm{C}-{ }^{1} \mathrm{H}$ interactions produce splitting of individual carbon signals, requiring the use of proton decoupling radiofrequency signals to eliminate these interactions. An advantage of the ${ }^{13} \mathrm{C}$ nucleus is that it offers superior separation of the individual resonances, important in view of the diversity of biologically active carbon containing molecules, carbohydrates, peptides, lipids, etc. (12). This study describes ${ }^{13} \mathrm{C}$ TMR spectroscopy techniques for the noninvasive, in vivo determination of adipose tissue PUFA and MUFA content in patients with CF and normal controls.

\section{MATERIALS AND METHODS}

Nine outpatients with CF from the University of California, Davis, Cystic Fibrosis Center volunteered for this study. All CF patients had sweat chloride concentrations of more than $60 \mathrm{mEq} /$ liter measured by pilocarpine iontophoresis (13). The percent ideal body weight (weight for height), triceps skinfold percentile, and Schwachman clinical scores were determined for each patient (14-16). Serum carotene (normal $=40-200 \mu \mathrm{g} / \mathrm{dl}$ ) was measured by standard clinical laboratory techniques. Eight of the CF patients had steatorrhea for which they were taking oral pancreatic enzyme replacement therapy. One CF patient had normal 72-h coefficient of fat absorption and bentiromide-PABA pancreatic function testing. One 24-yr-old female CF patient 
required supplemental oxygen and was receiving $2500 \mathrm{cal} /$ day as Isocal HCN via gastrostomy tube. Seventeen normal controls were pediatric and adult volunteers who underwent similar anthropometric evaluation. All studies were approved by the $\mathrm{Hu}-$ man Subjects Committee of the University of California Davis Medical Center and informed consent was obtained from all subjects.

TMR spectra were obtained on an Oxford Research Systems TMR-32 operating at 1.9 tesla with a horizontal clear bore of 20 $\mathrm{cm}$. A paired concentric surface coil probe was used with an outer ${ }^{1} \mathrm{H}$ decoupling coil $3 \mathrm{~cm}$ in diameter and an inner ${ }^{13} \mathrm{C}$ coil measuring $2.0 \mathrm{~cm}(17-19)$. The ${ }^{13} \mathrm{C}$ coil has an active sampling volume of about $7 \mathrm{ml}$. The probe was placed in a plastic stage protecting the coils from damage, yet allowing the tissue to be studied to be placed less than $1 \mathrm{~mm}$ from the plane of the coils. The patients reclined on a bed allowing the lower leg to rest over the coils in the center of the magnet. Shimming, optimizing the homogeneity of the magnetic field in the sample area, was accomplished by maximizing the integration of the $\mathrm{H}_{2} \mathrm{O}$ signal obtained from the ${ }^{1} \mathrm{H}$ probe. Continuous single frequency decoupling was performed by applying a constant low power $(200$ MW) radiofrequency signal at the frequency of the protons attached to unsaturated carbons in order to remove ${ }^{1} \mathrm{H}^{13} \mathrm{C}$ interactions, this also minimized any potential tissue heating. ${ }^{13} \mathrm{C}$ studies were obtained by applying a $7 \mu$ s pulse every $0.25 \mathrm{~s}$ for 2048 acquisitions, requiring about $8 \mathrm{~min}$. The resulting free induction decay containing $2 \mathrm{~K}$ data points was zero-filled to 8 $\mathrm{K}$ and $5 \mathrm{~Hz}$ Gaussian line broadening was applied before Fourier transformation. All spectra were plotted from $0-200 \mathrm{ppm}$ and areas of interest plotted in $10 \mathrm{ppm}$ increments. We have recently described the details of these methods, including comparison to standard gas chromatographic techniques (19).

Relative PUFA content was determined by dividing the peak height of the internal polyunsaturated carbon signal (128 ppm) by the height of the carboxyl signal (173 ppm) (Fig. 1). MUFA

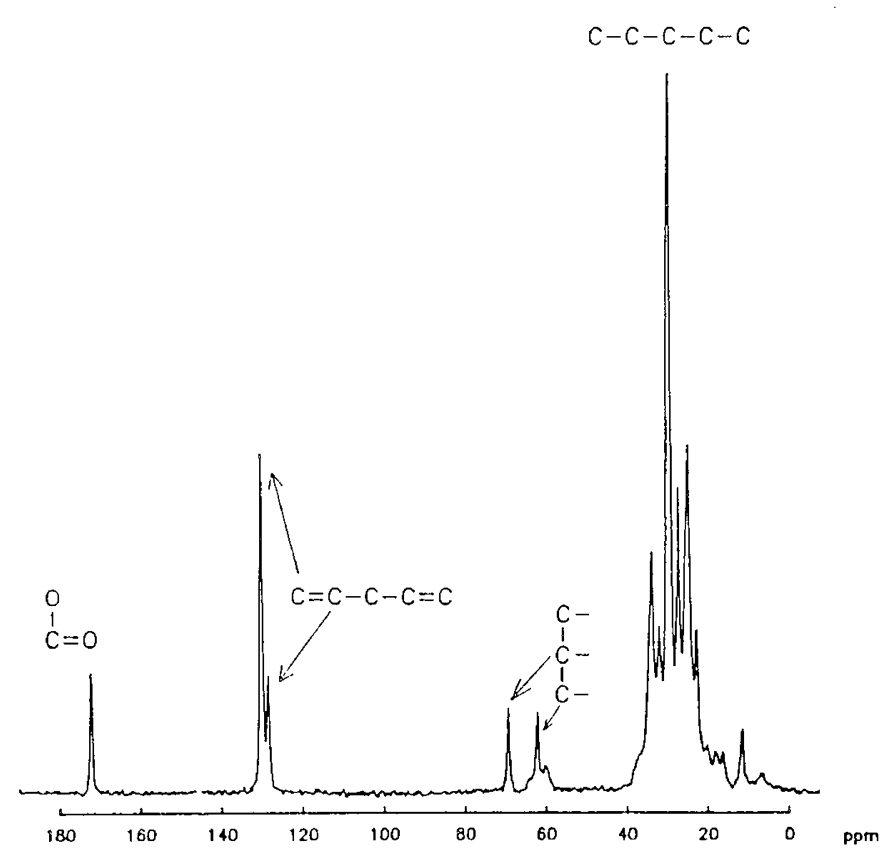

Fig. 1. Typical natural abundance ${ }^{13} \mathrm{C}$ TMR spectra of human adipose tissue with individual carbon resonances as noted. The larger unsaturated peak at $130 \mathrm{ppm}$ represents external unsaturated carbons and is found in all unsaturated molecules, whereas the smaller peak at $128 \mathrm{ppm}$ corresponds to only the internal unsaturated carbons, specific for polyunsaturated molecules. The peak at $69 \mathrm{ppm}$ represents 2 -glycerol carbon backbone and the $62 \mathrm{ppm}$ peak is the 1,3-glycerol carbons. The broad shoulder at 62 ppm represents incomplete proton-carbon decoupling. content was determined by subtracting the $128 \mathrm{ppm}$ signal from the total unsaturated signal (external carbon, $130 \mathrm{ppm}$ ) and dividing by the carboxyl signal. These ratios were then multiplied by a correction factor (21.4) based on previous T1 (spin-lattice) and nuclear Overhauser effect determinations (19). All results are expressed as mean \pm SD unless otherwise indicated and results were compared by unpaired, two-tailed $t$ tests.

\section{RESULTS}

The characteristics of the $\mathrm{CF}$ and control populations are summarized in Table 1. No significant differences were noted in age, percent ideal body weight, or triceps skinfold percentiles. The CF patient without steatorrhea had higher triceps skinfold percentiles $(60 \%)$ and serum carotene $(69 \mu \mathrm{g} / \mathrm{dl})$ than the other $\mathrm{CF}$ patients. The patient receiving gastrostomy feedings had 10 percentile triceps skinfolds, $75 \%$ ideal body weight, and carotene and cholesterol levels similar to the other CF patients.

Using TMR, PUFA, and MUFA content was $17.8 \pm 2.1 \%$ $(14.9-21.4 \%)$ and $44.8 \pm 3.8 \%(33.6-48.8 \%)$ in normal volunteers, whereas in CF patients values of $15.0 \pm 2.0 \%(12.7-18.8 \%)$ $(p<0.005$ versus normal) and $47.8 \pm 6.5 \%(38.5-61.3 \%)$ (NS), respectively, were observed. The PUFA results of all subjects are compared to age in Figure 2. These values did not correlate with triceps skinfold percentile (Fig. 3), percent ideal body weight, age, Schwachman clinical score, or serum carotene. The $\mathrm{CF}$ patient without malabsorption had abnormal PUFA content of $13.7 \%$, whereas the CF patient receiving supplemental gastrostomy feeds had PUFA content in the normal range, $18.8 \%$. If the results from the gastrostomy-supplemented patient are removed, the differences between $\mathrm{CF}$ and normals become more pronounced, reaching significance levels of $p<0.001$ and $p<$ 0.04 for PUFA and MUFA.

\section{DISCUSSION}

This study demonstrates significant differences in adipose tissue composition between CF patients and normal controls. Although the differences were statistically significant, some overlap was noted between normal and CF children less than $15 \mathrm{yr}$ of age, and between normals and the one CF patient receiving caloric supplementation via gastrostomy tube. The significance of the abnormal EFA status found in $\mathrm{CF}$ patients remains unanswered. Initial studies supported the hypothesis that abnormal EFA status was secondary to malabsorption and inadequate caloric intake (20). However, further investigations did not document an improvement in EFA status in patients receiving pancreatic enzyme supplements despite a substantial decrease in steatorrhea $(5,7,20)$. Abnormal EFA levels have been demonstrated in several circulating membrane lipid classes in CF patients without malabsorption and in CF heterozygotes $(8,21)$.

There is some evidence that abnormal EFA metabolism may be part of the underlying disorder in CF. Abnormalities in cord blood EFA in infants with CF suggest that a fundamental defect of fat metabolism may be in part responsible for the clinical manifestations of this disease (22). Several investigators have reported abnormalities of prostaglandin metabolism in CF patients $(2,4)$. One report has demonstrated elevation in sweat chloride concentration in a non-CF infant receiving long-term $\mathrm{PGE}_{1}$ infusion, with normalization after cessation of $\mathrm{PGE}_{1}$ therapy (23). In vitro studies have demonstrated abnormal regulation of incorporation and turnover of EFA in erythrocytes and lymphocytes taken from $\mathrm{CF}$ patients $(4,9)$. Our findings in the $\mathrm{CF}$ patient with normal fat absorption also suggest some form of an underlying disorder of EFA metabolism independent of fat malabsorption or a pattern of malabsorption not detectable by standard balance studies. The normal results in the CF patient receiving high calorie gastrostomy feedings demonstrate the ability to correct the reduced levels of EFA in adipose by providing sufficiently high caloric intake. This supports the hypothesis that 
Table 1. Patient data

\begin{tabular}{|c|c|c|c|c|c|c|c|}
\hline Patients & $n$ & Sex & Age & Skinfold (\%) & $\begin{array}{c}\text { Ideal body } \\
\text { wt }(\%)\end{array}$ & $\begin{array}{c}\text { Schwachman } \\
\text { score }\end{array}$ & $\begin{array}{l}\text { Carotene } \\
(\mu \mathrm{g} / \mathrm{dl})\end{array}$ \\
\hline $\mathrm{CF}$ & 9 & $3 \mathrm{~F} 6 \mathrm{M}$ & $18.0 \pm 10.5$ & $33.6 \pm 23.1$ & $95.7 \pm 13.2$ & $52.5 \pm 10.3$ & $25.9 \pm 18.6$ \\
\hline Normals & 17 & $8 \mathrm{~F} 9 \mathrm{M}$ & $\begin{array}{c}22.2 \pm 12.8 \\
\mathrm{NS}^{*}\end{array}$ & $\begin{array}{c}40.2 \pm 33.7 \\
\text { NS }\end{array}$ & $\begin{array}{c}100.4 \pm 8.5 \\
\text { NS }\end{array}$ & & \\
\hline
\end{tabular}

* Not significant at $p<0.05$.

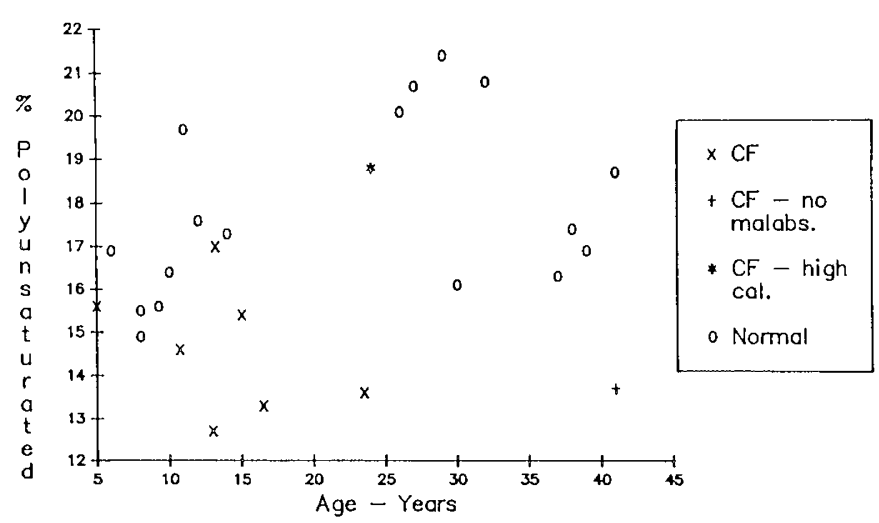

Fig. 2. Adipose tissue PUFA content compared to age. Significant overlap was noted in subjects less than $15 \mathrm{yr}$ of age. The CF patient without fat malabsorption is clearly in the lower range, whereas the $\mathrm{CF}$ patient receiving high calorie supplemental feeds is clearly in the normal range.

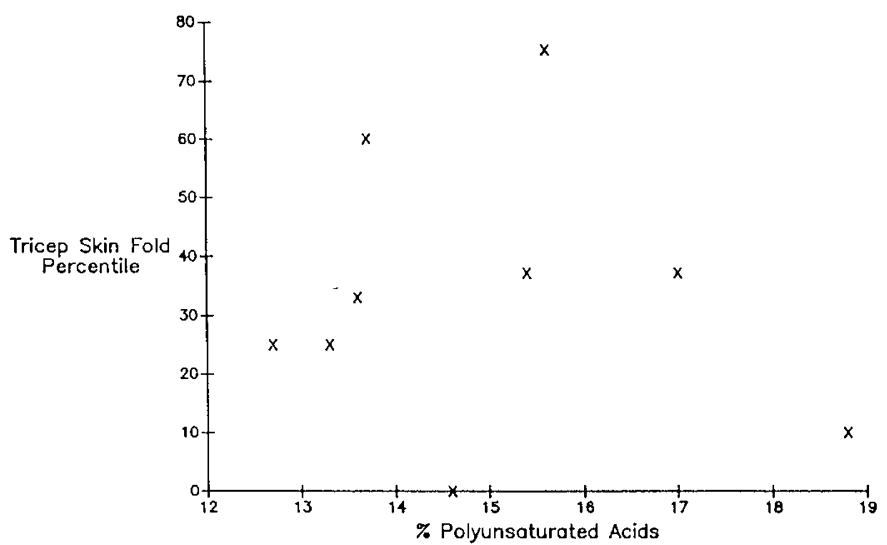

Fig. 3. Triceps skinfold percentile compared to observed adipose tissue PUFA levels. No significant correlation between these quantitative and qualitative adipose tissue measurements $\left(R^{2}=0.12\right)$ was demonstrated.

sufficient caloric intake will prevent EFA from being used as an energy source, permitting their use for essential biochemical functions.

EFA deficiency is thought to play a significant role in the clinical status of CF patients. Animal models of EFA deficiency have demonstrated abnormalities in pulmonary defense mechanisms similar to those seen in patients with $\mathrm{CF}$ (24). Some patient studies have correlated clinical status with the degree of EFA abnormalities, but the classic clinical findings of EFA deficiency are rare in $\mathrm{CF}(3,6)$. In our patient studies a correlation between clinical score and EFA status was not observed, but this may be limited by the fact that the patients under study were only mildly afflicted. Although initial studies aimed at correcting the EFA abnormalities in CF did produce biochemical and clinical improvement, further studies have not been able to reproduce all of these findings $(22,25-27)$. Unfortunately several of the supplementation studies (using medium-chain triglycerides, safflower oil, intravenous fat, etc.) involving $C F$ patients may not have provided adequate levels of caloric and/or EFA substrates. Our finding of normal adipose EFA in the one patient undergoing substantial caloric supplementation may underscore the importance of increased total caloric intake in order to improve EFA status.

In our study percent ideal body weight and triceps skinfold percentiles were used to estimate nutritional status. These measurements serve as an estimate of generalized nutritional status and total body fat content and have been used in other studies of CF patients (27). Our results demonstrate a lack of correlation between observed adipose PUFA content and triceps skinfold percentile (Fig. 3) or percent ideal body weight, indicating that these quantitative measurements alone may not provide an adequate qualitative estimate of fat stores or EFA status.

The noninvasive nature of TMR spectroscopy permits the safe evaluation of both normal children and patients with abnormalities in fat absorption and metabolism avoiding invasive techniques such as adipose biopsies. This technique may be used to optimize nutritional support of $\mathrm{CF}$ patients and we anticipate initiating studies to address the effects of EFA supplementation versus total caloric supplementation.

\section{REFERENCES}

1. Insull W Jr, Bartsch GE 1967 Fatty acid composition of human adipose tissue related to age, sex, and race. Am J Clin Nutr 20:13-23

2. Chase EP, Dupont J 1978 Abnormal levels of prostaglandins and fatty acids in blood of children with cystic fibrosis. Lancet 2:236-238

3. Hubbard VS, Dunn GD 1980 Fatty acid composition of erythrocyte phospholipids from patients with cystic fibrosis. Clin Chim Acta 102:115-118

4. Rogers V, Dab I, Michotte Y, Vercruysse A, Crokaert R, Vis H 1984 Abnormal fatty acid turnover in the phospholipids of the red blood cell membranes of cystic fibrosis patients (in vitro study) Pediatr Res 18:704-709

5. Kuo PT, Huang NN, Bassett DR 1962 The fatty acid composition of the serum chylomicron and adipose tissue of children with cystic fibrosis of the pancreas. J Pediatr 60:394-403

6. Farrell PM, Mischler EH, Engle MJ, Brown DJ, Lou SM 1985 Fatty acid abnormalities in cystic fibrosis. Pediatr Res 19:104-109

7. Galabert C, Filliat M, Chazalette JP 1978 Fatty acid composition of serum lecithin in cystic fibrosis patients without steatorrhea. Lancet $2: 903$

8. Rogiers V, Dab I, Crokaert R, Vis HL 1980 Long chain nonesterfied fatty acid pattern in plasma of cystic fibrosis patients and their parents. Pediatr Res 14:1088-1091

9. Carlstedt-Duke J, Bronnegard M, Strandvik B 1986 Pathological regulation of arachidonic acid release in cystic fibrosis: the putative basic defect. Proc Nat Acad Sci USA 83:9202-9206

10. Chance B, Eleff S, Leigh JS, Sokolow D, Sapega A 1981 Mitochondrial regulation of phosphocreatine/inorganic phosphate ratios in exercising human muscle: a gated 31P NMR study. Proc Natl Acad Sci USA 78:67146718

11. Arnold DL, Matthews PM, Radda GK 1984 Metabolic recovery after exercise and assessment of mitochondrial function in-vivo in human skeletal muscle by means of ${ }^{31} \mathrm{P}-\mathrm{NMR}$. Magnetic Resonance Med 1:307

12. Canioni $P$, Alger JR, Schulman RG 1983 Natural abundance carbon-13 NMR spectroscopy of liver and adipose tissue of the living rat. Biochem 22:49744980

13. Gibson LE, Cooke RE 1959 A test for concentration of electrolytes in sweat in cystic fibrosis of pancreas utilizing pilocarpine by iontophoresis. Pediatrics 23:545-549

14. Hamill PVV, Drizd TA, Johnson CL 1976 NCHS growth charts-1976. Monthly vital statistics report (HBA), Rockville, MD, 25(suppl):76

15. Frisancho AR 1981 New norms of upper limb fat and muscle areas for assessment of nutritional status. Am J Clin Nutr 34:2540-2545

16. Schwachman H, Kulczycki LL 1958 Long term study of one hundred five patients with cystic fibrosis. Am J Dis Child 96:6

17. Dimand RJ, Moonen CTW, Bradbury EM, Cox KL 1987 Non-invasive determination of linoleic acid content of adipose tissue by carbon-13 topographic magnetic resonance. Clin Res 13:228(abstr)

18. Moonen CTW, Oberhansli R, Galloway R, Rajagopalan B, Radda GK 1985 
Non-invasive measurement of polyunsaturated fatty acids in human fat by C-13 magnetic resonance spectroscopy. Clin Sci 68:29(abstr)

19. Moonen CTW, Dimand RJ, Cox KL 1988 The noninvasive determination of linoleic acid content of human adipose tissue by natural abundance Carbon13 nuclear magnetic resonance. Magnetic Resonance Med 6:140-157

20. Hubbard VS, Dunn GD, di Sant'Agnese PA 1977 Abnormal fatty acid composition of plasma lipids in cystic fibrosis. A primary or secondary defect? Lancet 2:1302-1304

21. Burns GB, Dodge JA 1982 Elevated levels of 13,14-dihydro-15-keto prostaglandin metabolites and essential fatty acid deficiency in cystic fibrosis and heterozoygote subjects. In: Bavan D (ed) Proceedings of the 11th Annual Meeting of the European Working Group on Cystic Fibrosis, June 1982, Brussels, Belgium, ACCO, Leuven, Belgium, p 76

22. Lloyd-Still JD, Johnson SB, Holman RT 1981 Essential fatty acid status in cystic fibrosis and effects of safflower oil supplementation. Am J Clin Nutr $24: 1-7$
23. Silverman BL, Lloyd-Still JD, Hazinski TA, Hunt CE 1985 Increased sweat chloride levels associated with prostaglandin $E_{\mathrm{I}}$ infusion. J Pediatr 106:953954

24. Harper TB, Chase HP, Henson J, Henson PM 1982 Essential fatty acid deficiency in the rabbit as a model of nutritional impairment in cystic fibrosis. Am Rev Respir Dis 126:540-547

25. Elliott RB 1976 A therapeutic trial of fatty acid supplementation in cystic fibrosis. Pediatrics 57:474-479

26. Mischler EH, Parrell SW, Farrell PM, Raynor WJ, Lemen RJ 1986 Correction of linoleic acid deficiency in cystic fibrosis. Pediatr Res 20:36-41

27. Gibson RA, Teubner JK, Haines K, Cooper DM, Davidson GP 1986 Relationships between pulmonary function and plasma fatty acid levels in cystic fibrosis patients. J Pediatr Gastroenterol Nutr 5:408-415

28. O'Loughlin E, Forbes D, Parsons H, Scott B, Cooper D, Gall G 1986 Nutritional rehabilitation of malnourished patients with cystic fibrosis. Am $\mathrm{J}$ Clin Nut 43:732-737 